\title{
UM PRECURSOR DO COMÉRCIO FRANCÊS NO BRASIL (II)
}

\author{
(Continuaçāo)
}

Da carta partida (36). Ao entrar na primerta parte. de seu livro, pois as considerações que até agora apresentamos acham-se subordinadas à "Introduçāo", recomendava Gallès, sob o titulo "De la Charte-Partie", que se tivesse todo o cuidado, nos contratos de fretamento para viagens aos portos do Brasil, em nāo assumir compromissos para o regresso à Europa, dada a dificuldade que havia, não raro, em obter-se frete para qualquer país.

Mas, se por interêsse reciproco, o afretador e o armador fôssem tentados a ajustar viagem de ida e volta, era importante nāo determinar o pôrto exato a que deveria retornar a embarcaçāo. Bordeaux e Nantes, advertia Gallès, eram cidades pràticamente condenadas, pois para elas jamais seria encontrado carregamento. E para o próprio Havre, o pôrto mais comumente usado, havia amiúde falta de frete.

No caso, porém, em que a carta partida facultasse optar por três ou quatro portos, deveriam ser escolhidos, sem hesitação, os de Marselha, Antuérpia e Hamburgo. Mas se a escolha se restringisse apenas a dois, entāo seria aconselhável decidir pelos do Havre e Antuérpia.

Medida de prudência era, também, dadas as oscilações cambiais, determinar no conhecimento o modo de pagamento do frete,

(36). - Carta partida era o contrato firmado entre o comerciante e o mestre ou o proprietário do navio, para o transporte das mercadorias. Ferreira Borges, em seu "Diccionario Juridico-Commercial", esclarece que a denominação carta paxtida provem de que outrora se partia a carta de fretamento, ficando metade em poder do fretador e a outra metade em poder do afretador, juntando-se as duas, quando havia necessidade de dirimir duvidas (Achiles Bevilaqua, "Código Comercial Brasileiro". 3." ed., Rio de Janeiro, 1935, pág. 199).

o "Diccionario Maritimo Brazileiro organizado por uma commissão nomeada pelo Governo Imperial", sob a direcão do Barão de Angra e publicado no Rio de Janeiro em 1877, definia a carta partida como "carta de fretamento de que se fazem dois contextos semelhantes na mesma folha, que se corta pelo meio, dando uma ao fretador do navio e ficando outra em poder do dono ou seu consignatario". Entretanto. nessa altura, já o Código Comercial Brasileiro, que é de 1850 . estabelecia, em seu artigo 566, que "o instrumento, que se chama carta partida ou carta de fretamento, deve ser assinado pelo fretador e afretador, e por quaisquer outras pessoas que intervenham no contrato, do qual se dará a cada uma das partes um exemplar". 
- qual, pard evitar-se surpresas desagradáveis a qualquer das partes contratantes, deveria ser estipulado, com tôda a precisão, "à táxa do câmbio do dia da chegada do navio ao Brasil". E o nosso viajante acrescentava: "Par cette précaution, qu'indique l'expérience, les intérêts des deux parties sont à coubert; en agissant ainsi, l'affréteur paiera dans le pays ce qu'il a eu réellement l'intention de payer. Opérer différemment c'est s'exposer à des partes effrayantes; c'est traiter en aveugle sur les nuances les plus délicates".

Dai Gallès condenar veementemente o sistema às vêzes adoĩado, que consistia em estabelecer, por exemplo, um câmbio médio pâra o pagamento do frete, baseado na cotação do franco em relação ao mil réis, na data do contrato. Tratava-se, a seu ver, de jôgo imprudente e arriscado para ambas as partes interessadas, pois, de acôrdo com a maré dos acontecimentos politicos, o franco tanto podia descer a 180 , como subir a 360 réis.

$\mathrm{E}$, mais uma vez, prevenia seus compatriotas contra os perigos de uma cláusula contratual menos segura sôbre o pagamento do frete, ou de uma designaçāo descuidada para o retôrno do navio: "Conheci uma casa", diz êle, "que prêsa à sua carta partida, foi forçada; por falta de frete para os portos nela indicados e por causa de um câmbio que nāo houvera sido previsto, a pagar nāo apenas o frete quase em dôbro para a viagem de ida, mas também o frete de volta, sem ter uma só tonelada de mercadoria a bordo".

A época do ano que Gallès recomendava para as viagens da França ao Brasil, tendo em vista as condições atmosféricas, compreendia os meses de setembro a março, sendo que o mais favorável era o de dezembro. Nāo deveria, porém, o armador empreender a expediçāo, sem estar ciente do número de navios saídos ou a sair de todos os portos da França, com destino a estas paragens.

Pernambuco. "Ville de Fernambouc, ou Pernambuco", é como Gallés denomina o Recife, ao iniciar suas observações sôbre esta capital, que êle identifica sempre com o nome da província, o que, aliás, nāo é raro em livros de outros viajantes.

Após indicar a posiçāo geográfica da cidade, advertia os navegantes dos perigos que o pôrto oferecia às embarcações de grande calado, sobretudo nas ocasióes de mau tempo. "Il faut attendre le pilote", recomendava êle, "qui, pour les faire entrer, va chercher les navires à une lieue environ du récif". E continuava, numa boa amostra de seu poder descritivo: "Le premier objet qui frappe 1'oeil du voyageur, à Fernambouc, cest le rocher qui en borde la rade; il a quarante lieues environ de longueur, et il semblerait que la nature le posa là tout exprès pour défendre la ville qui devait se bâtir un jour vis-à-vis de lui, et la protéger contre les fureurs 
des hommes et des élémens... Cette roche forme une ligne absolument droite; on dirait une muraille élevée par les habitans du pays, dans le même but que les Chinois construisirent jadis la leur, avec cette différence, toutefois, qu'elle n'a que la hauteur nécessaire pour garantir le port contre les débordemens: à la mer basse, elle ressort de quatre à cinq pieds sur mer, et quoiqu'elle semble coupée à de certaines distances, il faut se garder de commettre la moindre imprudence entre les espaces, car, malgré qu'ils paraissent présenter un passage libre, ils n'en sont toujours pas moins la continuation du récif, seulement la superficie en diffère".

E Gallès nāo esconde, também, sua admiraçāo pelos jangadeiros que, em suas toscas e estranhas embarcações, que êle tenta descrever (37), se aventuravam mar a dentro, enfrentando os maiores perigos, "com uma calma e um sangue frio que escapam à imaginaçāo do europeu".

O comércio no Recife, segundo o autor de "Du Brésil", era bastante intenso em relaçāo à populaçāo, embora os artigos de luxo, quer em matéria de vestuário, quer de comestiveis, nāo pudessem deixar de ter um consumo restrito, pois para cada homem branco contavam-se cêrca de dezesseis de côr (38).

Quanto aos artigos franceses, ainda nāo estavam ali muito difundidos, o que, em sua opiniāo, deveria atribuir-se, principalmente, à ausência acentuada de nobres e funcionários naquela provincia, bem como à falta de arte e elegância com que a mercadoria era exposta nos poucos magazines existentes.

As sêdas de Lyon que, há dois anos, vinham tendo no Recife aceitaçāo digna de registro, poderiam tornar-se artigo de grande saida, quando naquela cidade fôssem montados estabelecimentos como os do Rio de Janeiro (39). Nesta capital, esclarecia Gallès,

\footnotetext{
(37). - Maria Graham, quando de sua passagem por Pernambuco, anotou em seu diário: "The jangada resembles nothing I have ever seen before" (op. cit. pág. 29).

(38). - Não é demais repetir quanto são imprecisos e contraditórios os dadus estatísticos conhecidos sobre a população do Brasil, até o primeiro recenseamento geral de 1872 . A relação entre pretos e brancos, no Recife, apresentada por Gallès, é, sen dúvida, exageradíssima. A "Memoria Estatistica do Imperio do Brazil", de autor anónimo, escrita. em 1829 e oferecida ao Marquês de Caravelas, una das fontes mais citadas, atribui a Pernambuco, em 1823 , a população de 480.000 habitantes, sendo 330.000 livres e 150.000 escravos. O Recife e Boa-Vista terian 50.000 almas ("Revista do Instituto Histórico e Geográfico Bra. sileiro", n." LVIIT, pág. 96).

(39). - A moda francesa. embora Gallès não acentui aqui êsse particular, como o faz adiante, ao tratar da Bahia e Rio de Janeiro, já se impunha, no Recife, ao gósto feminino. Maria Graham, anos antes, ao descrever em seu diário um grupo de pessoas, que vinha do sertão, acentua: "I. was vexed that the woman of the party wore a dress evidently of French fashion: it spoiled the unity of the groupe" (op. cit., pág. 106). Livro que retrata, com nitidez, a influencia francesa em Pernambuco, na primeira metade do século passado, é "Um engenheiro frances no Brasil". de Gilberto Freyre (Rio de Janeiro, 1940).
} 
"enquanto os produtos de nossa indústria não foram apresentados com luxo e magnificência, seu consumo foi limitado e muito lento; mas desde que passamos a exibí-los com a pompa mágica que atrai, fazendo nascer a necessidade, sua voga cresceu à voz da fama: em todos os tempos e em tôda a parte a beleza que se esconde sob os andrajos da miséria passa desapercebida, não fere o olhar".

Comércio importante, que a França poderia estabelecer, também, com a província de Pernambuco, no qual, aliás, uma casa de Marselha já estava empenhada, era o dos vinhos. E Gallès faz, nesta altura, uma advertência, que nāo fica nada a dever à que se encontra na comunicação da "Secretaria Principal do Comércio de França às principais Câmaras do Comércio do Reino", a que já tivemos oportunidade de referir-nos neste trabalho (40). Diz êle: "mais comme les Brésiliens ne boivent généralement que l'o-porto, le noeud gordien serait d'imiter parfaitement cette dernière qualité, tant pour le liquide que pour le logement, et l'on sentira que je ne puis indiquer ce moyen que verbalement. Si l'imitation n'est pas comme identique, l'essai tournera en chance de perte ou de gain. $\mathrm{Si}$, au contraire, l'on parvient au point voulu pour la consommation, j'évalue que cette ville seule pourrait nous offrir un débouché annuel de 2.500 à 3.000 tonneaux de nos vins".

Os vinhos franceses tinham, ainda, venda reduzida, porque só quase os estrangeiros os consumiam. E eram os vinhos de Saint-Loubés (perto de Bordeaux), que ofereciam melhores possibilidades, nāo só pelo seu preço moderado, como pela sua resistência ao calor da zona tórrida, o que nāo acontecia com os de outra origem, que muitas vêzes sofriam completa deterioraçāo.

Eram bem aceitos, também, os vinhos de Champagne, de espuma artificial, "mas sempre em caixas de doze garrafas", recomendava Gallès, "e dos preços comuns de 1,75 a 2 francos a garrafa, pois os pernambucanos gostam dêste vinho, sem conhecer-lhe as qualidades." Os de Alicante, Madeira, Málaga, julgava êle que proporcionavam grandes perdas ao exportador, o que acontecia. também, com os azeites em geral.

Quanto à aguardente, seu consumo não se operava na propurção do da Bahia e Rio de Janeiro, devendo, entretanto, essa bebida ser considerada como um bom artigo para quem fizesse uma viagem direta a Pernambuco.

Entre as mercadorias de fácil venda, contavam-se os chamados queijos de Holanda, em pequenas caixas, e as farinhas e comestiveis franceses, desde que bem apresentados e a preços normais. Grande aceitaçāo tinham, igualmente, os artigos de vidro, os de armarinho, as quinquilharias em geral. E nāo deixavam de

(40). - Vide nota 23. 
ter seus apreciadores os sabões de Marselha (41), as anchovas em conserva, as amêndoas, nozes, etc., devendo, porém, haver a necessária moderação na remessa do calçado forte de homem e do de setim de mulher.

As sêdas, tornava a insistir o autor de "Du Brésil", requeriam a mais séria e escrupulosa atenção, pois os artigos muito finos escoavam-se lentamente $e$ os de inferior qualidade ficavam quase todos encalhados. Era necessário, portanto, fazer o sortimento em artigos de mediana qualidade, sem perder de vista que as sêdas de Lyon nāo deveriam deixar nada que desejar em brilho e vivacidade de côres, das quais as preferidas eram o azul celeste, o preto, o rosa vivo, o branco e, com mais moderaçāo, o verde.

$E$ acentuando um dos traços do caráter provinciano, esclarecia o nosso cronista: "os compradores de Pernambuco preocupam-se mais com o brilho (das fazendas) do que com a qualidade, diferença notável a estabelecer com o Rio de Janeiro, onde o bom deve acompanhar o belo":

Quanto aos produtos da Provincia, informava Gallès a seus compatriotas que eram o algodāo, o café, o fumo, em grandes quantidades, e $\circ$ anil, o arroz, a ipecacuanha, o anis, em doses limitadas. "A colheita de algodāo", escrevia êle, "é a mais importante, pois todos nós sabemos que o algodão de Pernambuco é reputado na Europa como um dos melhores que produzem as terras da zona tórrida (42); assim, nāo é raro que os navios, depois de venderem sua carga no Rio de Janeiro ou Montevideo, venham abastecer-se em Pernambuco, para a viagem de retôrno".

Os couros de Pernambuco, conhecidos no comércio, segundo observa Gallès, sob o nome de couros do Brasil, eram de qualidade bem inferior aos do Rio de Janeiro, e, principalmente, aos de Montevideo, êstes mais belos, mais pesados e mais bem cortados, os quais só eram excedidos pelos de Buenos Aires.

E passando ao reino mineral, o autor de "Du Brésil". com a franqueza que não lhe é rara, escreve: "On compte plusieurs mines de fer, de cuivre et d'argent dans les alentours de la ville. La lenteur, la presque nullité de leur exploitation, font dire que ces trésors, qui pourraient être en Europe des sources de richesses, ne sont pour ces contrées que des monumens de l'ignorance et de l'obscurité des hommes que les habitent".

(41). - "O Sabão de Marselha hade no Brasil ser preferido ao Sabão Inglez, se lhe abaixarem o preço", dizia o opúsculo com que se relaciona a nota 23 .

(42). - James Henderson também observava, em 1821: "O alıodão de Pernambuco é o melhor do Brasil, o que decorre, em parte, da rigorosa inspeção por que êle passa" (op. cit., pág. 390). 
Bem mais amável foi o retrato que descortinou de seus patrícios, ac observar que "les Français y sont très-bien vus, et il est flatteur de pouvoir dire que leur conduite commande l'estime et le respect de tous".

$\mathrm{E}$ ao encerrar seus comentários sôbre o Recife, anotava Gallès que as profissões ali mais lucrativas eram as de padeiro, carniceiro. sapateiro, alfaiate, serralheiro e funileiro.

Bahia. Dando à capital o nome da província, pelo qual era também conhecida, escrevia o autor de "Du Brésil", sem dúvida pouco versado na divisāo administrativa do país: "Esta cidade, antigamente a capital do Brasil, sob o nome de Sāo Salvador, é maior e mais importante que Pernambuco e as outras províncias: contam-se ai cêrca de cem mil almas". E informava que a proporção entre negros e brancos nāo era tão elevada quanto no Recife (43).

Sua descriçāo da baia de Todos os Santos, "onde as frotas mais consideráveis encontrariam um lugar cômodo e seguro", sem necessidade de pilôto para nela entrarem, também nos parece digna de transcrição: "Au côté oriental de l'entrée principale, la terre s'élève en amphithéâtre. Depuis le rivage on distingue la ville basse et la ville haute; cette dernière est bâtie sur un terrain inégal, et il faut gravir une montagne de dix minutes pour y parvenir. Les cocotiers, orangers et bananiers qui entourent et séparent les habitations, offrent une fraîche et continuelle verdure, susceptible de charmer l'oeil de l'homme le plus insensible aux beautés de la nature. A de certaines distances on dirait que ces arbres si beaux, si majestueux, ont leurs racines sur les toits des maisons qu'ils ne font cependant qu'environner".

$\mathrm{Na}$ cidade alta é que residiam as autoridades e a aristocracia local, sendo que do terraço do teatro descortinava-se um panorama que Gallès qualifica de "o mais pitoresco, o mais sublime da América meridional". Mas a cidade baixa, "suja e repugnante de imundícies", causou-lhe triste impressāo: "suas ruas sāo estreitas e mal calçadas e é de admirar que os odores mefíticos, numa regiāo tāo

(43). - Esta afirmativa não devia corresponder a realidade, una vez que pelo porto do Salvador, durante todo o tráfico negreiro, segundo os dados conhecidos, ingressou número de escravos muito superior ao que deu entrada por Pernambuco (Ver Maurício Croulart, "Escravidão Africana no Brasil". São Paulo, 1949).

A "Memoria Estatistica do Imperio do Brazil", citada na nota 3S, dava à Bahia, em 1823, a população de 671.922 habitantes, dos quais 434.464 livres, e 237.458, escravos; na capital contavam-se 60.000 habitantes. Spix e Martius calcularam a população do Recóncavo em 200.000 almas. 
próxima do equador, nāo provoquem mais sérias conseqüências na saúde de seus habitantes".

Embora o comércio da cidade do Salvador não fôsse tāo intenso quanto o do Recife, levando-se em conta as respectivas populações, - observava o nosso cronista - aquela capital correspondia, em relaçāo às regióes que a circundavam e que nela se abasteciam, ao que representava Limoges para Poitou e Angoumois, na França.

Elemento perturbador, escrevia êle, das transações mercantis, eram as freqüentes revoluções que assolavam o nosso país. Quando de sua passagem pela Bahia, em dezembro de 1827, "todos os magazines acabavam de ser fechados, e o comércio estava em completa estagnaçāo, em virtude da circulação de moeda falsa, que as autoridades queriam obrigar a aceitar" (44). E Gallès continua: "Os conflitos foram muito sérios e o govêrno soube resolvê-los com um decreto cheio, ao mesmo tempo, de energia e de eqüidade. A moeda falsa foi rejeitada e os espíritos se acalmaram, senāo de fato, pelo menos na aparência. Três méses depois uma conspiraçāo estalou, mas sabe-se que os seus efeitos foram sufocados" (45).

As modas francesas principiavam, entretanto, a exercer seu dominio na cidade, ao qual nem as próprias pretas livres escapavam. "O colete, o vestido, o chapéu", dizia Gallès, "da garrida baiana já passam pelas māos de nossas modistas e costureiras" (46). E como as lojas de modas ainda nāo eram ali muito numerosas, achava êle que as modistas que deixavam a França anda-

(44). - Trata-se da chamada crise do "xem-xem", nome dado a moeda de cobre falso, que circulava abundantemente na Bahia, com desastroso reflexo nas finanças da província.

Receiosos os comerciantes de que o novo presidente da província. brigadeiro José Egídio Gordilho de Barbuda. pretendesse tomar medidas contra aquela moeda, passaram a recusá-la ou a vender as mercadorias a precos exorbitantes. Ante a reacão do povo, o comércjo conservou-se fechado no dia 21 de novembro de 1827 (fato a que alucie Galles), o que obrigou o presidente da província a publicar um bando. compelindo-o a abrir suas portas e. consequentemente, a aceitar a moeda em circulação, até que providências ulteriores dessem solução à crise (Inácio Accioli de Cerqueira e Silva, "Memórias Históricas e Políticas da Provincin da Bahia", anotadas pelo Dr. Braz do Amaral, Bahia, 1933, vol. VI págs. 231 e seguintes).

(45). - O Decreto de 27 de novembro de 1827 é que determinou as medidas que deviam ser tomadas, para o resgate de tôda a moeda de cobre que girava na Bahia. As instruçōes para a sua execug̣ão foram baixadas com o Decreto de 4 de dezembro de 1827 , que nomeou a José Egidio Gordilho de Barbuda, presidente da província, Antônio Vaz de Carvalho, Pedro Ferreira Bandeira e Joaquim José de Oliveira para lhes darem cumprimento, "na qualidade de Comissários imediatos do Govêrno".

40). - I ainda Maria Graham quem anotava, em seu diario, após uma festa na casa do consul ingles, quando de sua estada na Bahia: "The senhoras were all dressed after the French fashion: corset, fichu, garniture, all was proper, and even elegant, and there was a great display of jewels" (op. cit., pág. 142). 
riam mais bem avisadas em dirigir-se para lá, do que ir aumentar a concorrência que entre elas existia no Rio de Janeiro.

Mas Salvador conservava ainda os vestigios de seu esplendor de antiga capital e sabia ter em melhor conta os artigos de luxo do que o Recife. Era de esperar, pois, que ainda viesse, numa situaçāo mais estável, a oferecer grandes escoadouros ao comércio francês. $E$ isso naturalmente se daria quando seus habitantes, nāo mais tormentados pelas idéias de republicanismo, houvessem sentido "todos os benefícios do sistema das monarquias constitucionais".

E Gallès que, anos mais tarde, irá testemunhar, em verso, sua devoçāo a Luiz Felipe, "le Roi-citoyen", pontifica, num conceito à La Palisse:. "C'est en goûtant d'un fruit qu'on apprécie l'arbre qui l'a produit".

Infelizmente, poucos sāo os dados que o autor de "Du Brésil" oferece sôbre o comércio francês na Bahia. Limita-se a esclarecer que os artigos, que deveriam ser levados para lá, eram pràticamente os mesmos, que referira ao tratar de Pernambuco, só que em maior quantidade. Necessário era, no entanto, que êles tivessem melhor aparência e fôssem de mais sólida confecçāo. Os azeites e os vinhos moscatéis vendiam-se com facilidade e poderiam proporcionar bons lucros, em ocasiāo de falta dêsses produtos no mercado.

A Alfândega do Salvador, que contava, também, com uma Bolsa bastante moderna, era mais severa do que a do Recife. "On n'entre que chapeau bas dans ces deux établissemens", esclarecia Gallès, admirado, sem dúvida, da civilidade baiana.

Quanto aos produtos locais, eram os mesmos que os de Pernambuco, em menor volume, sendo de notar, ainda, que o seu algodāo era de qualidade inferior ao daquela provincia. As laranjas passavam, entretanto, "por ser as melhores e mais belas do mundo".

Nào deu Gallès, também, maiores esclarecimentos sôbre outros aspectos da vida da capital da Bahia, dizendo apenas que "les arts et les métiers y vivent presque généralement dans une heureuse aisance".

Rio de Janeiro. A baía do Rio de Janeiro não podia deixar de provocar em Gallès as mesmas frases de admiraçāo com que se expressaram quase todos os estrangeiros que a ela aporta- 
ram. "La baie de cette capitale touche au gigantesque, au sublime", exclama êle, lembrando que o almirante Roussin afirmara nāo existir outra semelhante no mundo (47).

A capital do Império oferecia aos olhos de nosso viajante um "aspecto bem mais europeu do que as provincias", o que devia ser atribuido ao esplendor natural da côrte, onde os altos personagens ostentavam "um luxo verdadeiramente asiático".

Neste "luxo asiático" andava, com certeza, um pouco de imaginaçāo de Gallès, embora se deva reconhecer que o quadro da cidade, por êle pintado, parece não haver ficado longe do original: "A beleza das praças e das ruas principais, a riqueza, a elegância dos magazines franceses (48), o bulicio e a atividade que o comércio provoca, o grande número de estrangeiros que habitam esta capital, o movimento extraordinário de entrada e saida dos navios mercantes de tôdas as nações, o aspecto de uma alfândega imensa onde pilhas de mercadorias aparecem $e$ desaparecem sem cessar, formam o conjunto de um quadro que o viajante está longe de esperar, ao desembarcar numa terra em que aparecem tāo visiveis os sinais da escravidāo".

O palácio do imperador, situado à beira-mar (atual praça 15 de Novembro), embora "de uma arquitetura bastante moderna", não the pareceu bonito, nada tendo visto de notável, também, na residência de São Cristóvāo. "ce Versailles brésilien", que, aliás, se encontrava em reformas. A Câmara dos Deputados, o Senado, a capela imperial, assim como as igrejas em geral eram os monumentos mais cuidados e os que mais se aproximavam da "arquitetura contemporânea".

A respeito da anarquia monetária, entāo existente no pais, nāo deixa Gallès de fazer, também, alguns breves reparos. Pouco claras sāo suas observações sôbre a criaçāo do Banco do Brasil, parecendo que êle nāo tinha idéia muito segura das causas que a determinaram, nem da época em que tal acontecimento se verificou: "Le Portugal et l'Angleterre ayant épuisé les trésors de cette ca-

(47). - A opinião de Roussin acha-se ligeiramente deturpada, pois ele escreveu apenas: "La baie de Rio-Janeiro est très spacieuse, et l'une des plus magnifiques du monde"' (op. clt., pág. 90).

(48). - í de estranhar que Galles não houvesse feito referência especial à rua do Ouvidor, o centro da moda de então, que fazia lembrar aos viajantes ingléses a Regent Streot, de Londres, e aos franceses, a rue Vivienne, de Paris. O Barão de Bougainville, na sua viagem de circunavegaçáo, com as corvetas "La Thétis" e "L'Esperance", ao passar pelo Rio de Janeiro em março de 1826, um ano antes, pois, de Gallès ali haver estado, escrevia em seu diário: "Après les églises, le théatre et le musée, je ne sais rien a Rio qui merite la curiosité des voyageurs, si ce n'est peut-etre la rue d'ouvidor, la plus marchande de la ville et la seule qui soit digne d'une capitale" ("Journal de la Navigation autour du Globe", 1837, pág. 613). 
pitale (Rio de Janeiro) sous le règne du roi Juan VI, cette catastrophe, jointe aux difficultés qu'éprouvait le commerce dans ses. transactions journalières par suite de la mauvaise administration. des finances, suggéra l'idée à une société de négocians et de capita-. listes de se faire autoriser par le gouvernement à installer une ban-. que. Le roi acquiesça à cette demande, et les fondemens de cetétablissement furent basés sur des immeubles et des capitaux immenses".

$E$, como se vê, nāo foi Gallès bem informado, também, a respeito da base - "imóveis e capitais imensos" - em que diz haverassentado o Banco do Brasil, pois, em carta régia de 22 de agôsto. de 1812, era o próprio principe regente quem, reconhecendo o pouco interêsse que o estabelecimento despertara para a aplicação de capitais, encarregava os governadores das capitanias de solicitar "a. efetiva cooperação de todos os capitalistas, proprietários, negocian-. tes e empregados públicos", que estivessem "nas circunstâncias de concorrer ao cofre do Banco" (49).

A desvalorização do papel-moeda, emitido pelo Banco, 'nāo: teve, outrossim, o ponto de partida por êle indicado, ou seja, a guerra com a República Argentina, declarada em 1825. Tal desvalorizaçāo vinha, pode-se dizer, desde a fundaçāo do estabelecimento, agravando-se de dia para dia, em virtude da crescente inflaçāo de moeda fiduciária (50). A êste respeito, parece-nos interessante o depoimento de Gallès: "Hoje nāo se vê no Rio senāo papel em tôdas as transações. O cobre, a prata e o ouro encontram-se ai a preços tăo excessivos, que os comerciantes preferem. vender suas mercadorias $30 \%$, em cobre, $55 \%$, em prata, e $88 \%$, em ouro, abaixo do que êles pedem em papel. Em outros têrmos. êste papel perde $30 \%, 55 \%$ e $88 \%$ de seu valor, segundo o metal. por que é trocado".

$\mathrm{E}$, ao contrário do que previa Gallès, a crise por que passava. o Banco, não obstante os sacrificios que fazia para enfrentar a delicada situaçāo financeira do Império, nāo cessou com o término. da guerra com a Argentina. Assinado o tratado de paz em 1828 .

(49). - Os subscritores de ações do Banco, que mais se distinguissem, seriam. contemplados, prometia essa carta régia, "com honras e mercés". Afonso Arinos de Melo Franco, em seu importante livro, "História do Banco do Brasil", transcreve (págs. 48-49) curiosas informaçōes sóbre a concessão de tais favores.

Não era sem razão que Mathison escrevia: "The sale of patents of nobility, star, crosses, and habitos do Christo, or insignia of the Order of Christ, and others similar to it, was among the most innocent, and at the same time lucrative, expedients for raising money. The rage for these decorations attained a greater height at Rio that. it had perhaps ever before done in any country; almost every petty shopkeeper might be seen in the streets with his habito do christo". (op. cit., pág. 136).

(50). - Afonso Arinos de Melo Franco, op. cit., págs. 25-26. 

dar riquezas incalculáveis ao Brasil, pois às pedras preciosas ela junta as mais importantes minas de ferro e ouro, sendo favorecida, ainda, por um dos melhores climas do Brasil".

Quanto à província de Mato Grosso, fértil não só em minas de ouro e prata, como de ferro e diamantes, dizia: "Acerca de quarenta anos foi extraida de uma terra denominada Sapateyro (traz êsse nome porque, na verdade, um sapateiro é que a descobriu) (52) a quantidade de 42 arrobas de ouro (1.340 libras), no espaço de nove dias; e o que custará a crer, mas que é pura verdade, conforme se poderá verificar nos arquivos da provincia, é que, num dos lugares em que hoje está edificada a cidade de Cuyaba, local conhecido sob c nome de Ernesto, foram tiradas, durante trinta e cinco dias, por ocasiāo de sua descoberta, 400 arrobas de ouro (12.800 libras)!" (53).

Parece, pois, que Gallès, espantado com os prodigios de um passado remoto, não percebera que o ciclo da mineração agonizava no Brasil. Daí sua observação: "Eis os informes mais exatos e mais circunstanciados que podem ser dados sôbre as minas e cursos de água do Brasil, e, tendo em vista o que acabo de expor, presumo que me assiste o direito de mais uma vez repetir que a França náo dá prova de zelar por seus interêsses, quando se descura de estreitar relações com êste vasto e rico império".

$E$, no seu entender, "um capitalista que se decidisse a passar cinco anos, com uma dúzia de homens capazes e trezentos trabalhadores brancos, numa das quatro províncias citadas, poderia estar certo de realizar o décuplo do capital empregado, após fazer os necessários acordos com o govêrno para a sua exploraçăo".

Mas nāo eram só as minas que ofereciam extraordinárias possibilidades de ganho a quem quisesse trabalhar: "J'évalue", aduzia o autor de "Du Brésil", "que l'on peut également décupler ses capitaux en achetant une Fasenda (plantation) de café, et la faisant cultiver soi-même pendant sept à huit ans: l'on peut considérer

(52). - Alfredo Moreira Pinto, em sua já citada obra, "A pontamentos para o Diccionario Geographico do Brazil", escreve: "Saputeiro: Lugarejo situado em uma chapada a 4 léguas a $O$. da cidade de Cuiabá, o qual fêz-se notável por uma lavra de ouro, que aí se repartiu em 1789. Com pouca extensão, era muito rica. Na lata do superintendente, que era de 12 palmos de largura e 30 braças de fundo, e já havia sido devastada por ladrōes, tiraram-se assim mesmo mais de mil oitavas de ouro (B. de Melgaço)".

(53). - O cronista .José Barbosa de Sá, em sua "Relaçāo das povoaçoens do Cuyabá e Mato groso de seos principios thé os prezentes tempos", dá notícia minuciosa da descoberta destas lavras, feitas por Miguel sutil em 1722, no local depois chamado "Tanque de Arnesto". Diz êle: "Avalloouce tirarse deste Lugar dentro em lium mes melhor de quatrocentas arobas de ouro sem que os socavbens profundasem mais de tres the quatro palmos" ("Anais da Biblioteca Nacional", n.॰ 23, Rio de Janeiro, 1901). interessante notar que, relacionado com os sobreviventes da frota saida en maio de 1730 de Cuiabá, com destino a São Paulo, e dizimada pelos indios Paiaguás, encontra-se um médico alemão, chamado Ernesto Lambert ( $F$. A. de Varnhagen," "História Geral do Brasil", 4." eđ.. São Paulo, 1948, págs. 128-130). Presumimos que se trate da mesma pessoa que mereceu ter seu nome associado a topografia da então vila de cuiabá. 
chaque pied de café comme rapportant net la valeur de un franc (l'Europe en paix). Différens propriétaires m'ayant soumis le produit de leurs récoltes, toutes proportions prises, je ne puis guère m'éloigner de plus de cinq à sept centimes et demi, selon les nuances et la qualité de la graine, qui, comme nous le savons, diffèrent suivant la situation des terres où se trouve la plantation".

A exploraçāo de engenhos de açúcar já nāo lhe parecia negócio tão aconselhável por causa da dispendiosa mão de obra. Mas "uma fiaçāo de algodāo, estabelecida em Sāo Paulo, com o devido número de tecelöes, seria susceptivel de produzir lucros avantajados a quem a criasse".

$\mathrm{E}$ Gallès, que, como se vê, era homem de intuiçāo, esclarecia: "E bastante dizer, para dar idéia dêsses lucros, que a matéria prima é obtida no local a duas ou três patacas a arroba (cêrca de 4 francos por 30 libras) e que as necessidades desta provincia sāo da mais alta importância, em virtude de seu luxo (54) e de sua grande populaçāo (55). Encaminho esta nota às meditações do capitalista, assegurando-lhe que não há operaçāo bancária que possa produzir melhores resultados" (56).

Tudo quanto acabamos de expor, sob o titulo de "Rio de Janeiro", sāo digressões de caráter geral, a que Gallès naturalmente não quis furtar-se, no intúito de melhor chamar a atenção de seus compatriotas, talvez com exagerado otimismo, para as possibilidades desta parte, tão ignorada, do novo mundo.

(54). - O luxo, na opinião de outros viajantes, não era a nota característica dos costumes paulistas. Spix e Martius (op. cit., 2.0 vol., pág. 12) e Rugendas (op. cit., pág. 99), em épocas pouco distantes, acentuam, ao contrário, a sua sobriedade, principalmente no mobiliário das habitações.

(55). - De acórdo com a já citada "Memória Estatística" (nota 38), a Província de São Paulo, contava, em 1823, com 280.000 habitantes, dos quais 259.000 livres. e 21.000 escravos. Saint-Hilaire, entretanto, orcava a população de São Paulo, no ano de 1826, em 258.901 habitantes (Augusto de Saint-Hilaire, "Viagem à Provincia de São Paulo", tradução de Rubens Borba de Morais, 2. ed., São Faulo, 1945, págs. 84-85).

(56). - Nesta predição de Gallès, sóbre os promissores resultados que poderia proporcionar uma fiação de algodão em São Paulo, não pretendemos ver uma profecia sobre o futuro da cidade que viria a transformar-se no maior centro industrial da América do Sul. Mas o que nos parece interessante $\hat{e}$, de certo modo, a afinidade de sua observação com $o$ que mais tarde Saint-Hilaire escreveria: "Já em outro ponto fiz sentir que o Brasil deve permanecer ainda como pais simplesmente agrícola e que não chegou a época em que lhe pode ser vantajoso estabelecer manufaturas: entretanto, quando for momento propicio para isso, em São Paulo que tais empreendimentos devem ser iniciados" (op. cit., pág. 181). Sobre os primórdios da indústria de tecidos em São Paulo, devem ser lidos os artigos de Sérgio Buarque de Holanda, publicados no "Digesto Económico", de novembro de 1947 ("Fiação e Tecelagem em São Paulo na Era Colonial"), abril de 1948 ("A mals antiga fábrica de tecidos de São Paulo") e outubro de 1948 ("Fiacão Domética em São Paulo"). 
Nāo se esquecia, porém, de que a capital do Império era o melhor mercado para a colocação dos produtos de sua pátria. "O consumo do Rio de Janeiro", declarava êle, "está acima de tudo quanto se possa descrever; os artigos franceses sāo ali de fácil venda, quando belos e de boa qualidade; é para lá, sòmente, que podem ser levados objetos de luxo, de todos os preços, desde que escolhidos ao gôsto do país. As pessoas de relêvo fazem questāo de seguir as modas francesas e não há mulher acima da classe vulgar, que nāo seja vestida pelas nossas modistas e costureiras. E lembrando palavras de D. Pedro I, num galanteio à Marquesa de Gabriac, acrescentava: "Les dames de la cour suivent absolument le genre parisien, et il semble tout naturel que ce soit sur l'ambassadrice française qu'on doive toujours prendre les nuances des grâces et du bon ton" (57).

Daí a razāo porque o teatro do Rio de Janeiro, com sua bela sala de espetáculos, apresentava "um aspecto surpreendente ao olhar do viajante: correspondessem os atores à sua magnificência e deixasse-se o espectador levar apenas pelo aparato das damas seria tentado a crer-se na Grande Ópera".

Mas, evidentemente, a um bom comerciante nāo bastava que as modas seguissem o figurino francês: E Gallès advertia: "As nossas manufaturas de tecidos poderiam encontrar um grande consumo no Brasil e, principalmente, no Rio de Janeiro, desde que se dedicassem a fabricar, para estas regióes, tecidos leves, finos,

(57). - Raro foi o viajante, que andou pelo Brasil nas primeiras décadas do século XIX, que deixou de acentuar o crescente predominio da moda francesa, principalmente no Rio de Janeiro. As brasileiras, segundo Hippolyte Taunay, podiam disputar, em elegancia, com as parisienses (op. cit., II vol., pág. 45).

Debret, na explicação de seu desenho "Un funcionário a passeio com sua famflia", ao referir-se ao que esbocara, quando de seu primeiro encontro com senhoras brasileiras, vestidas ainda num misto d $\epsilon$ moda "anglo-portuguêsa, importada pela Côrte de Lisboa e na qual há oito anos nada se mudara". escreve: "Fiz imediatamente um desenho, mas o resultado, pela sua exatidão, foi uma verdadeira caricatura inútil de reproduzir, porque não exprime em absoluto o caráter $e$ temperamento brasileiros, pois o habitante do Brasil tem-se mostrado, desđe então, tão entusiástico apreciador da elegancia e da moda francesas que, por ocasião de minha partida, em fins de 1831, a rua do Ouvidor (rua Vivienne, de París, no Rio) era quase inteiramente constituida de lojas francesas de todo tipo, mantidas pela prosperidade de seu comércio", (op. cit., tomo I, pág. 126).

Mas no próprio ano (1816), em que a chamada “Missão Artística Francesa", de que Debret fazia parte, aportou ao Irasil, Luiz Joaquim dos Santos Marrocos, nas célebres cartas dirigidas do Rio de Janeiro à familia em Portugal, escrevia a sua irmã: "Nāo posso explicar-te a abundancia e fartura das fazendas, e quinquilherias Francezas, q. tem inundado esta Cidc., fazendo negaças ao dinheiro: já se não vê fazendas Inglezas, $q$. todas tem sido abandonadas, e toda a gente se vé ataviada ao gosto Francez, menos eu q. sou Portugal velho, e ninguem me tira desta scisma. Este porto se ve coalhado de Navios Francezes, q. so no mez passado entrarão 29 carregados de bugiarias...". ("Anais da Biblioteca Nacional do IRio de Janeiro", vol. 56. carta n. 0 184. Esta carta, aliás, não tem data, mas constam dela notícias idênticas às que o autor transmitia a seu pai na carta n. ${ }^{\circ} 105$. de 21 de setembro de 1816). 
com muito brilho e aparência (58); em resumo, seria necessário trabalhar segundo as amostras inglẹsas e estabelecer a mercadoria a preços idênticos aos delas; só assim nossas manufaturas poderiam rivalizar com as da Grā-Bretanha, do contrário terāo que contentar-se com os sobejos que elas deixarem" (59). E, em sua opiniāo, enviar ao Brasil tecidos pesados, fortes, encorpados, que exigiam mais trabalho e matéria prima, era perder tempo e dinheiro. Dêstes artigos, jamais se conseguiria vender o côvado acima de 3.600 a 3.400 réis.

A França, entretanto, já levava a palma à Inglaterra, numa de suas especialidades: "As sêdas francesas sāo as preferidas no Rio de Janeiro; êste artigo tem grande consumo e oferece magníficas vantagens, quando é trabalhado ao gôsto do país: é necessário nāo conduzir outras côres que nāo sejam o branco, o preto, - azul-celeste, o rosa vivo e um pouco de verde. Para os outros watizes há uma diferença de $40 \%$ a $50 \%$ " (60).

$\mathrm{E}$, em matéria de tecidos, Gallès acrescentava, ainda, alguns dados sôbre a moda feminina: "Je désignerai comme objets principaux les satins unis, satins ouvrés, fịchus ombrés et quadrillés, les châles 5 et $6 / 4$ riches: point de 4/4; robes lamées or ou argent, fausse blonde, rubans de ceinture, bandes brodées; châles de laine

(58). - Frase Erifada no original.

(59). - Do já referido opúsculo, "Documentos relativos ao Comércio dos Novos Estados da América..." (nota 23), transcrevemos as seguintes recomendaçōes que, em sua primeira parte, coincidem particularmente com as de Galles: "O Brasil recebe quantidades notáveis de tecidos fabricados em Inglaterra, e a França podia vantajosamente competir com ela a respeito destes artigos: porém era preciso assim neste ramo, como em outros muitos, que em França se adotasse o modo de fabricar inventado pelos ingléses, para abastecer a massa da população; porque é cm razão do delgado das suas chitas, ou pouco encorpado delas que êles as podem vender tão baratas: sendo porém de notar que, apesar de tudo, reconhecem ao menos a superioridade das nossas chitas, e bons tecidos, por isso que as fabricam com o selo das nossas manufaturas; o que mais ainda se prova, porque uma casa inglêsa do Maranhão fretou uma embarcação no Havre de Grace, e féz para lá remeter uma carregação de artigos das nossas manufaturas, naquelc mesmo momento, em que os seus armazens estavam sobrecarregados de fazendas inglêsas" (págs. 44-45).

(60). - Ainda do mesmo opúsculo, mencionado na nota anterior, consta, em aditamento, uma "Carta do Conselheiro de Jstado, Presidente do Tribunal do Commercio e Colonias, aos Membros da Camara de Commercio de Bayona", que faz referência a um relatório recebido, no qual, em virtude da interrupção das relaçōes do Brasil com as possessóes portuguêsas da fndia, situação essa de que a França poderia tirar "um partido vantajoso', "e recomendada a imitação dos estofos da China. I as especificaçōes' "sobre os debuxos, e medida a que dão preferência os consumidores do Brasil, especialmente a respeito desta qualidade de tecidos, por efeito dos hábitos, e do gôsto dos mesmos consumidores". são os seguintes:

- Cada peça deve ter 24 covados, nem mais, nem menos; cada covado, 25 polegadas; largura da sêda, 28 polegadas. $A$ peça há de ter 4 dobras, e dobrar-se ao comprimento de uma vara de $401 / 2$ polegadas. O sortimento das córes há de ser ó seguinte: Setim liso (na hipótese de 12 peças) 5 devem ser de azul-celeste, 3 da cor branca chamada da Pérsia, 2 verdes, 1 carmesim, e 1 roxa. Sêdas lavradas: 6 peças de azul-celeste, 2 de um cor de rosa vivo, 1 verde, 2 cor de ouro, e 1 branca. Uma terça parte da partida com colunas, e as outras duas terças partes com ramos grandes, e pequenos". 
boiteux, fond uni, 5 et $6 / 4$, etc., etc. Mais toujours du beau, du riche, de l'éclat, ou rien".

Como se vê, a aparência, naquele tempo, já era tudo, no Rio de Janeiro...

Os artigos de París e Lyon já se haviam imposto, exclusivamente, no mercado, de modo que muito se enganava, dizia Gallès, quem supunha que as sêdas francesas nāo tinham saída no Brasil; o que era inegável é que acarretavam prejuizo, fatalmente, as que nāo fôssem escolhidas ao gôsto indigena.

Algo havia, ainda, para disputar à Grā-Bretanha. no ramo de tecidos: "O consumo dos escravos oferece ao comércio inglês um escoadouro imenso aos panos fabricados, que lhes servem de vestuário. Este comércio deverá, entretanto, declinar incessantemente, pois, a datar de $10^{\circ}$ de janeiro de 1830 , o Brasil perderá o direito de fazer o tráfico dos negros, acrescendo, ainda, como é sabido, que a mortalidade que entre êles grassa excede a sua reproduçāo. A França poderia lutar vantajosamente com a Inglaterra neste importante ramo, mas seria necessário que ela procurasse igualar a leveza dos tecidos, o que, de maneira alguma, ainda fêz".

Nāo foi bom profeta, pois, o autor de "Du Brésil", quanto à reduçäo da freguesia dos panos ingleses, de inferior qualidade. A convençāo de 23 de novembro de 1826 , assinada entre o Brasil e a Inglaterra, segundo a qual, três anos depois da troca das ratificações do mesmo tratado, o comércio de escravos ficaria fora da lei, serviu, apenas, para acirrar os apetites dos que encontravam. no impedimento ao exercício de sua criminosa atividade, razāo para alcançar maiores lanços pela mercadoria importada com tantos riscos. Embora elevada, a mortalidade dos escravos foi, assim, largamente corrigida.

$\mathrm{Na}$ ordem de importância para o comércio francês no Brasil, o produto que se seguia aos tecidos era o vinho. E a êste respeito oferece Gallès interessantes informações sôbre o paladar dos habitantes do Rio de Janeiro de antanho.

"O consumo dos vinhos de Bordeaux, a propósito dos quais já falamos ao tratar de Pernambuco", esclarece êle, "é assaz considerável no Rio de Janeiro, em virtude da quantidade de franceses e estrangeiros que habitam esta capital, cujo número pode ser calculado em doze mil; o que dá um pouco mais de desenvolvimento a êste consumo é que os portuguêses começam a considerá-los bons para misturá-los com o vinho do Pôrto. Rio de Janeiro é a única cidade a que se pode levar, num carregamento, sem constituir imprudência, de cem a cento e vinte tonéis".

$E$, de novo, entramos em assunto delicado, embora Gallès nāo o ventile aqui com tanta franqueza, como o fêz ao tratar do co- 
mércio de Pernambuco: "Les vins dits Roussillons, imitant ceux de Catalogne, en pipes de cinquante à cinquante-cinq veltes, se vendent très couramment. Mais, je le répéterai, le point où les négocians de Bordeaux (que cet article regarde particulièrement) doivent viser avec la plus scrupuleuse attention, c'est l'imitation des vins d'Oporto: en parvenant à ce but essentiel, ils auraient un commerce immense à établir, et des bénéfices énormes à réaliser, puisque le cours de la pipe de ce vin, connu sous la dénomination de vinho do Porto \{eitoria, était, lors de mon départ (20 juillet), de 180 à 230.000 reis (6 a 800 francs la pipe). Que les faiseurs jugent si ce prix leur laisse de la marge, et si leur industrie n'est pas en défaut!".

Os vinhos de Champagne, em caixas de doze garrafas, tinham muita procura e eram pagos a bom preço, recomendando Gallès. entretanto, que só deveriam ser enviados os de espuma artificial, pela facilidade com que os demais se deterioravam, acarretando, evidentemente, graves prejuizos. E tais vinhos nāo deveriam ser de qualidade superior aos de dois francos a garrafa, na França.

Embora tivessem aceitaçāo, também, os vinhos moscatéis, "em gărrafas brancas, bem limpidas", nāo eram artigo dos mais aconselháveis, nāo sendo o seu consumo suficiente para a sua remessa en pipas.

Os vinhos de Madeira, Alicante e Málaga só mais tarde, talvez dentro de dez ou quinze anos, pudessem encontrar mercado no Brasil.

As aguardentes francesas eram, porém, muito estimadas em todo o pais, principalmente na Bahia e Rio de Janeiro, começando, também, os licores finos a ter os seus apreciadores, o que nāo obstava, em relação a êste artigo, ser necessário agir com bastante cuidado.

A quantidade de aguardente $3 / 6$ (61) deveria ser de vinte a trinta tonéis num carregamento. E Gallès aproveitava o ensejo para esclarecer: "duzentas toneladas, mais ou menos, é o que sempre entendo como carregamento, pois um navio de maiores dimensões nāo convém a êste país; eu presumo que um brick desta tonelagem encontrará, fàcilmente, frete para a volta, enquanto que uma embarcaçāo- de trezentas a trezentas e cincoenta toneladas ficará, às vêzes, dois a três meses no pôrto, sem conseguir carga".

Além dos tecidos e vinhos, outros artigos pesavam no comércio francês com o Brasil.

(61). - 3/6 era o tipo de álcool, do qual derivava a aguardente, como se vé da seguinte definicẫo: "Trois-Six n.m. Alcool dont la force est telle qu'avec trois parties (en poids) de cet alcool, mélangées à un poids égal d'eau, on obtient six parties d"eau-de-vie ordinaire" ("Nouveau Petit Larousse Illustré". 5." ed., París, 1950). 
"Nossos azeites e, sobretudo, nossos sabões", escrevia Gallès, "nāo estāo longe de se tornarem os mais procurados. Os sabões espanhóis que, ainda há pouco, eram os preferidos, perdem, de dia para dia, a sua fama". E recomendava, então, que os sabões fôssem acondicionados em pequenas caixas, de 40 a 50 libras, "susceptiveis de serem transportadas em costado de mula, para facilitar sua venda pelo interior".

As farinhas de Moissac, de primeira qualidade, escoavam-se Fàcilmente, com boa margem de lucro. Era importante, porém, não comprimi-las demais nos barris, para evitar seu empedramento. E a época em que tal artigo poderia proporcionar melhores resultados era depois de junho e até outubro, periodo em que as remessas dos Estados Unidos da América, desta mercadoria, eram quase nulas (62).

Produto digno de séria atençāo dos exportadores eram os couros de bezerro, que ofereciam possibilidade de grandes lucros, desde que fôssem convenientemente preparados e se tivesse o cuidado de marcá-los com a palavra "Nantes", pois, esclarecia o nosso viaiante, os couros da Bretanha eram considerados no Brasil como os melhores.

E lá vinha uma de suas advertências, digna das manobras altistas de nossos dias: "Si, par l'effet de circonstances imprévues, l'article se trouvait abondant et à vil prix (ce qui est susceptible de se présenter une ou deux fois dans l'année), je conseille au subrécargue ou capitaine de ne point vendre alors même qu'il dût attendre cinq et six mois pour réaliser; il peut être certain de bien opérer en agissant ainsi, car la consommation amèle le besoin, et celui-ci se faisant sentir à deux ou trois époques différentes, la hausse est dès lors inévitable".

$O$ interior das habitações principiava, entāo, pelo que informa o autor de "Du Brésil", a merecer mais atenção de seus moradores, cuja noção de beleza e confôrto não era, antes, das mais apuradas: "Nossos papéis pintados, que até agora acarretavam prejuizo certo, estāo em vias de fazer parte dos artigos que devem ser enviados ao Rio de Janeiro, mas sòmente quando escolhidos com bom gôsto. A alta classe, que, ainda há pouco, recebia em peças ruas, começa a ornar seus salões com ricas tapeçarias aveludadas, de belas e elegantes cercaduras sôbre fundo vermelho, azul vivo, rosa carregado".

$\mathrm{E}$ ao incluir a essência de terebentina entre as mercadorias que tinham apreciável consumo no Rio de Janeiro, dava Gallès a entender que a influência francesa ia mais longe ainda: "et main-

(62). - O Rev. R. Walsh, que esteve no Brasil na mesma época em que Galles, observou: "De oitenta a noventa mil barris de farimha são anualmente consumidos no Rio e suas dependencias, os quais são quase exclusivamente supridos pelos Estados Unidos" ("Notices of Brazil in 1828 and 1829". Londres, 1830, pág. 449). 
tenant que les enseignes, les devantures, les magasins et les maisons se peignent comme en France, les besoins de ce liquide deviennent d'une certaine importance".

Outros artigos, embora secundários, prosseguia êle, não deveriam ser esquecidos num carregamento: "les pantoufles vertes et lilas, les souliers pour homme forts et larges, les chaussettes blanches en fil, les éventails chamarrés d'or avec figures, les eaux de Cologne en jolis flacons, la parfumerie en extrait d'odeur et la pommade seulement, la quincaillerie, les pointes de Paris, les cartes à jouer espagnoles et portuguaises, le papier à lettre, etc.". E a propósito de papel de carta, informava, em nota ao pé da página, que uma companhia de franceses e inglêses pretendia montạ uma fábrica nos arredores do Rio de Janeiro. Duvidava êle que tal empreendimento pudesse ir avante, pois no Brasil nāo havia mecanismos nem matérias primas.

E Gallès escrevia ainda, talvez com justificada vaidade: "Direi mesmo que, em tese geral, todos os objetos de nossas fábricas, pela elegância dos desenhos e o acabamento do trabalho, sobrepujam os das outras nações; mas o cuidado com que os confeccionamos colocá-nos na contingência de nāo poder vendê-los aos preços estabelecidos pelos consumidores, os quais, embora apreciando a superioridade de nossos artigos, dão, às vêzes, seduzidos pela modicidade do custo, preferência a outros de inferior qualidade" (63).

E num esclarecimento final a seus leitores, nesta parte de seu trabalho: "Les villes de Rio-Granda ( sic) et Montévidéo sont des places également très-importantes, mais la guerre paralyse tellement leur commerce, que jusqu'à nouvel ordre il ne peut nous convenir de diriger nos vues sur ces deux provinces du Brésil: les goûts et les modes de la première sont les mêmes qu'à Rio-Janeiro, et ceux de la dernière se rapprochent un peu plus des moeurs espagnoles".

GUILHERME DEVEZA.

(Continua no próximo número).

(63). - Não há dúvida, como, aliás, se evidencia por outras frases de seu trabalho, que Galles, ao escrever este perfodo, tinha em sua frente o folheto sobre o "comércio dos novos Estados da América", a cuja tradução portuguêsa (ver nota 23) mais de uma vez nos referimos e do qual passamos a copiar: "Pode-se enfim concluir com esta observação geral, que todos os gêneros dos fabricantes franceses têm primazia sóbre os das outras naçóes, tanto pela elegáncia dos debuxos, como pelo fino do tecido; porém que, sendo fabricados com todo o esmêro, não 6 possivel vendêlos pelo mesmo preço dos gêneros inglêses...". 